\title{
Effects of dietary melatonin on broiler chicken exposed to continuous lighting during the first two weeks of life
}

\author{
Renata RELIĆ ${ }^{1, a, ®}$, Zdenka ŠKRBIĆ ${ }^{2, b}$, Ivana BOŽIČKOVIĆ1,c, Miloš LUKIĆ \\ Veselin PETRIČEVIĆ ${ }^{2, e}$, Nikola DELIĆ ${ }^{2, f}$, Aleksandra BONDŽIĆ́ ${ }^{3, g}$, Duško VITOROVIĆ ${ }^{1, \mathrm{~h}}$ \\ ${ }^{1}$ University of Belgrade, Faculty of Agriculture, Department of Animal Science, Belgrade, Serbia; ${ }^{2}$ Institute for Animal Husbandry, \\ Department of Poultry Science, Belgrade, Serbia; ${ }^{3}$ University of Belgrade, VINČA Institute of Nuclear Sciences - National Institute \\ of the Republic of Serbia, Department of Physical Chemistry, Belgrade, Serbia \\ aORCID: 0000-0001-5320-7863; bORCID: 0000-0001-6090-6005; ' ${ }^{\mathrm{a} O R C I D: ~ 0000-0001-6151-4273 ; ~}$ \\ dORCID: 0000-0002-8560-3956; ' ORCID: 0000-0002-2421-8341; fORCID: 0000-0002-9084-6098; \\ gORCID: 0000-0002-7403-2318; ${ }^{\mathrm{h} O R C I D: 0000-0002-8334-8808}$ \\ ${ }^{\square}$ Corresponding author: rrelic@agrif.bg.ac.rs. \\ Received date: 25.01.2021 - Accepted date: 17.08.2021
}

\begin{abstract}
Intensive broiler chicken production involves different lighting regimes, which affects a natural cycle of secretion of melatonin, a hormone included in multiple physiological processes in a bird's body. This research aimed to determine the effects of dietary melatonin supplementation during the first two weeks of broiler chickens' life, bred under constant $24 \mathrm{~h}$ lighting, on their health and some hematological, biochemical, and production parameters. The study lasted 6 weeks. Three hundred and twenty 1-day chickens were divided into two groups (control - $\mathrm{C}$ and experimental - M), with four replications and 40 chickens in each replica. In the first two weeks (the first phase of the study), a continuous lighting mode 24L: 0D was applied. Group M was receiving a diet supplemented with $30 \mathrm{mg} / \mathrm{kg}$ synthetic melatonin only during the first phase. Group $\mathrm{C}$ had a diet without melatonin supplementation throughout the whole study. Melatonin addition had a statistically significant effect $(\mathrm{P}<0.01)$ on the mean values of body weight and daily weight gain at the end of the $1^{\text {st }}, 2^{\text {nd }}, 3^{\text {rd }}, 4^{\text {th }}, 5^{\text {th }}$, and $6^{\text {th }}$ week. The chickens of the experimental group have had a significantly higher value of the European Production Efficiency Factor $(\mathrm{EPEF})(\mathrm{P}<0.05)$. The results presented in this paper indicate a direct benefit in stress relief in broilers and a value of the organism's antioxidant system promotion, manifested by improved production performance and fattening efficiency.
\end{abstract}

Keywords: Broilers, light, melatonin, production, stress.

\section{Introduction}

Multiple physiological processes and forms of behavior of living beings show circadian rhythmicity (9). Synchronization of these processes in the organism is performed by biological pacemakers located in the retina, pineal gland, and hypothalamus of the birds (17). The pineal gland of birds comprises light receptors, pacemakers, and the outgoing signal - melatonin $(18,19)$. The circadian rhythm of melatonin is already established in the second trimester of chicken embryonic development, with the amplitude increasing until hatching (39). It is characterized by the increased synthesis during the night (darkness) and decreased production during the day (light).

Approximately $80 \%$ of melatonin in the bloodstream is produced by the pineal gland (14). Besides, melatonin is produced by cells of peripheral tissues and organs, such as enterochromaffin cells of small intestine mucosa. The production of melatonin in the gastrointestinal tract is associated with feed consumption, especially one rich in tryptophan (13) which is the precursor for melatonin synthesis (40).

Chickens take feed in the period of daylight. Therefore, there is the assumption that feed intake and growth are the highest in broilers reared in (nearly) continuous illumination (5). Broilers in intensive production are subjected to $23-24 \mathrm{~h}$ continuous artificial lighting in the first week of life. Continuous lighting at around 20 illuminance (lx) ensures that chickens acclimatize themselves properly to their environment, as indicated by optimal feed and water intakes (24). In the later stages of rearing, regimes with different photoperiods' duration are applied $(6,24,32,33)$.

Duration of lighting significantly affects melatonin synthesis, growth, and health status in chickens (41). It is expected that broilers exposed to continuous lighting have 
a significant deficit of melatonin in serum, while performance and health are improved in broilers exposed to intermittent lighting (5). Sun et al. (32) have determined a significantly higher level $(\mathrm{P}<0.05)$ of melatonin in broilers exposed to continuous lighting in the $16 \mathrm{~L}: 8 \mathrm{D}$ regime, in contrast to chickens exposed to constant and intermittent lighting - with a shorter total period of darkness.

Melatonin has multiple roles in the organism, and the most important relates to the participation in the antioxidative system and protection of cells from the harmful effects of free radicals (40). Insufficient melatonin secretion in broilers is associated with metabolic and physiological disorders, leading to breeding diseases and deaths, thus with economic losses and several negative aspects of animal welfare (14), including fearful response in broiler chickens (19). The results of several studies have shown that in regime with controlled lighting, supplementation of melatonin in feed, drinking water or parenterally had positive effects on health and immune status of chicken, growth performance, feed intake and conversion, the morphology of intestine mucosa, and growth hormone levels along with others $(1,3,12,31,38)$.

This research aimed to investigate the effects of melatonin food supplementation on broiler chicken bred under constant 24-hour lighting during the first two weeks of life on birds' health and some hematological, biochemical, and production parameters.

\section{Materials and Methods}

The trial was performed at the Experimental Broiler Farm of the Institute for Animal Husbandry, Belgrade, Serbia.

Housing conditions and nutrition of broilers: Three hundred and twenty $(n=320) 1$-day-old Ross 308 broiler chickens of both sex and uniform body mass $(41.1 \pm 3.1 \mathrm{~g})$ were used and kept in a floor system on a mat of chopped straw, in one room with group boxes for 40 broilers (10 heads $/ \mathrm{m}^{2}$ ). In the first two weeks, a continuous lighting (CL) mode 24L: 0D (light: darkness) was applied (a combination of the infrared bulb in the box and ordinary light bulbs in the facility, average light intensity $65 \mathrm{~lx}$ ). From days 15 to 38 recommended (7) lighting regime with 16L: 4D: 2L: 2D was applied and from days 39 to 42, scheduled with 23L: 1D (light intensity $20 \mathrm{~lx}$, ordinary light bulbs, measured by lux meter Testo 540, Testo, Germany). Feed and water were available ad libitum. For chickens' diets, three standard corn/soybean meal-based complete mash feeds were used (8): STARTER (from day 1 to 14 ) with $12.7 \mathrm{MJ} / \mathrm{kg}$ metabolic energy (ME) and $23.3 \%$ crude protein (CP); GROWER (from day 15 to 28 ) with $13 \mathrm{MJ} / \mathrm{kg} \mathrm{ME}$ and $21 \% \mathrm{CP}$; and FINISHER (from day 29 to 42) with $13.4 \mathrm{MJ} / \mathrm{kg} \mathrm{ME}$ and $18.7 \% \mathrm{CP}$. The health, behavior, and mortality of the chicken were monitored and recorded daily.
Experimental design: The experiment lasted 6 weeks and took place in two phases: from days 1 to 14 and from days 15 to 42 . Chickens were divided into two groups (control - $\mathrm{C}$ and experimental - $\mathrm{M}$ ), with four replications and 40 chickens in each replica. During the first phase, the experimental group (M) received a starter diet supplemented with $30 \mathrm{mg} / \mathrm{kg}$ synthetic melatonin, $\mathrm{N}-$ acetyl-5-methoxytryptamine (EINECS Number: 200-7977; purity 99\%; Elephant Co., Serbia), and during the second phase fed without melatonin. The control group (C) had a diet without melatonin supplementation throughout the whole period (6 weeks).

Blood parameters: At the end of the first phase, on day 14 , blood samples, from five randomly chosen and stunned chickens from each group, were collected by heart puncture (25) and using heparinized vacutainers (Lithium heparin, Demophorius Ltd, Cyprus). Total erythrocyte count (RBC, $x 10^{12} / \mathrm{L}$ ) was determined manually (28), using a hemocytometer (Neubauer-improved, Marienfeld, Germany) and with Hayem's solution addition (NRK Inženjering, Beograd). Hemoglobin concentration $(\mathrm{Hb}$, $\mathrm{g} / \mathrm{L}$ ) on an ADVIA 120 Hematology System apparatus (Siemens Healthcare, Germany) on the principle of flow cytometry (36) was measured. Hematocrit (Hct, \%) was determined by the microhematocrit method (28), by using Hawksley Micro Hematocrit Tube Reader (Hawksley, US). Blood samples previously were centrifuged at 13,000 rpm for 5 minutes (Becton Dickinson, USA). Hematological indices (MCV - Mean Corpuscular Volume; MCH - Mean Corpuscular Hemoglobin; MCHC - Mean Corpuscular Hemoglobin Concentration) were calculated by the following formulas (11):

$\mathrm{MCV}$ in $\mathrm{fl}=\mathrm{Hct}(\%) \times 10 / \mathrm{RBC}\left(10^{6} / \mathrm{L}\right)$

$\mathrm{MCH}$ in $\mathrm{pg}=\mathrm{Hgb}(\mathrm{g} / \mathrm{L}) / \mathrm{RBC}\left(10^{12} / \mathrm{L}\right)$

$\mathrm{MCHC}$ in $\mathrm{g} / \mathrm{L}=\mathrm{Hgb}(\mathrm{g} / \mathrm{L}) \times 100 / \mathrm{Hct}(\mathrm{L} / \mathrm{L})$

Total leukocyte number (WBC) was determined indirectly (28) from the relationship between the values obtained by counting the cells in the chamber and the stained blood smear (Wright solution, BioGnost, Croatia). Leukocyte formula (a percentage of heterophile, lymphocytes, monocytes, eosinophils, and basophils) was determined by the formula (28): Absolute number of leukocyte cell type $=$ cell number in $1 \mathrm{~L} \mathrm{x} \%$ leukocyte type cells $/ 100$.

The $\mathrm{H} / \mathrm{L}$ ratio was calculated by dividing the number of heterophils by the number of lymphocytes (21). Catalase activity was measured by Perkin Elmer (USA) Lambda 35 spectrophotometer with a thermostated 1.00 $\mathrm{cm}$ quartz cell and using chemicals: EDTA (SigmaAldrich, Germany), hydrogen peroxide $\left(33 \% \mathrm{H}_{2} \mathrm{O}_{2}\right)$, and potassium hydrogen phosphate $\left(\mathrm{K}_{2} \mathrm{HPO}_{4} \times 3 \mathrm{H}_{2} \mathrm{O}\right)$, both from Merck (Germany). The samples were centrifuged at $2000 \mathrm{rpm}$ for ten minutes. Plasma and buffy coat were removed by aspiration, and the erythrocytes were washed 
three times with cold $\left(4^{\circ} \mathrm{C}\right)$ saline and suspended in four volumes of deionized water. Erythrocyte debris was removed by centrifugation at $2000 \mathrm{rpm}$ for $20 \mathrm{~min}$. Erythrocyte lysates were diluted and stored at $-70^{\circ} \mathrm{C}$ until assayed. Catalase activity was determined by measuring the decrease in absorbance $\left(\mathrm{H}_{2} \mathrm{O}_{2}\right.$ degradation $)$ at $240 \mathrm{~nm}$ for three minutes (10), and the values have been expressed as $\mathrm{U} / \mathrm{ml}$. One unit $(\mathrm{U})$ of catalase activity is the amount of enzyme required to decompose one micromole of $\mathrm{H}_{2} \mathrm{O}_{2}$ per minute.

Production parameters: Individual body weight (BW, g) was measured when the chickens moved in and at the end of each week $\left(7^{\text {th }}, 14^{\text {th }}, 21^{\text {st }}, 28^{\text {th }}, 35^{\text {th }}\right.$, and $42^{\text {nd }}$ day). By the values of individual body weights of birds and feed consumption per box between the two measurements, for different periods of fattening following parameters were calculated: daily gain (WG, g), daily feed intake (FI, g/day per chicken), and feed conversion ratio (FCR, $\mathrm{kg}$ of feed $/ \mathrm{kg}$ of weight gain). For the entire duration of the experiment (42 days), the European Production Efficiency Factor (EPEF) was calculated, as a cumulative indicator of broiler fattening success based on average body weight, vitality, feed conversion, and fattening duration, according to the formula (7):

$$
\mathrm{EPEF}=\frac{\text { Live weight }(\mathrm{kg}) \times \text { Livability }(\%) \times 100}{\text { Age in days } \times \text { Feed Conversion Ratio }}
$$

Statistical analysis: For determination of the statistical significance of the results, appropriate parametric and nonparametric tests were used (MannWhitney test for blood and Tukey test for production parameters). The results were presented as text, graphs, and tables - as mean values and standard error (SE). Data processing was done using STATISTICA 8 (StatSoft, Inc., USA).

\section{Results}

Health status and mortality: Chickens of the control (C) and experimental group (M) have had a harmonious physique by the end of fattening, properly developed bone and muscle tissue, vivid temperament, and good condition. The feathers, skin, and visible mucous membranes were without peculiarities. Appetite was good, and the feces of the usual form. The ability to move actively and coordinate movements were harmonized, and muscle tone was expressed and preserved. Mortality was low and uniform between the groups $(0.63 \%$ in both groups).

Blood parameters: The melatonin supplementation to chicken diet did not show a statistically significant effect on the difference in the average values of hematological parameters $(\mathrm{P}>0.05)$, although they were slightly higher in group $\mathrm{M}$ compared to $\mathrm{C}$, as shown in the following order: $\mathrm{RBC}-2.03$ : $1.94 \times 10^{12} / \mathrm{L} ; \mathrm{Hb}-110.67$ : $103.5 \mathrm{~g} / \mathrm{L}$; Hct - 30.33: 28.75\%; MCV - 150.67: 149.25 fL; MCH - 54.93: 53.75 pg; MCHC -364.97: $360.00 \mathrm{~g} / \mathrm{L}$; and $\mathrm{WBC}-12.07: 10.25 \times 10^{9} / \mathrm{L}$.

The difference between the groups in the leukocyte formula is more noticeable (Fig. 1) but also without statistical significance $(\mathrm{P}>0.05)$.

Values of the $\mathrm{H} / \mathrm{L}$ ratio in groups $\mathrm{M}$ and $\mathrm{C}$ were 0.47 and 0.75 , respectively $(\mathrm{P}>0.05)$.

Differences between mean values for catalase activity were not statistically significant $(\mathrm{P}>0.05)$. The more pronounced activity of catalase in the group (M) is noticeable (Fig. 2).

Production parameters: Melatonin addition had a statistically significant effect $(\mathrm{P}<0.01)$ on the mean values of BW and WG (tables 1 and 2 ) at the end of the $1^{\text {st }}, 2^{\text {nd }}$, $3^{\text {rd }}, 4^{\text {th }}, 5^{\text {th }}$, and $6^{\text {th }}$ week.

Regarding the mean values of FI and FCR, no significant differences were found $(\mathrm{P}>0.05)$, although birds of the $\mathrm{M}$ group had better feed conversion in all weekly measurement periods (Tab. 2).

EPEF values for the fattening period of 42 days were $287.98 \pm 6.22$ for group $M$ and $259.58 \pm 5.35$ for group $C$, and these differences were statistically significant $(\mathrm{P}<0.05)$.

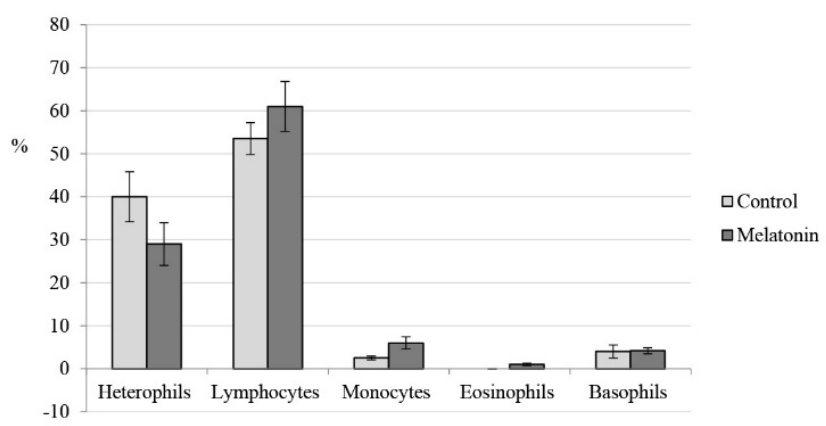

Fig. 1. Percentage distribution of individual leukocyte forms leukocyte formula (percentage $\pm \mathrm{SE}$ ).

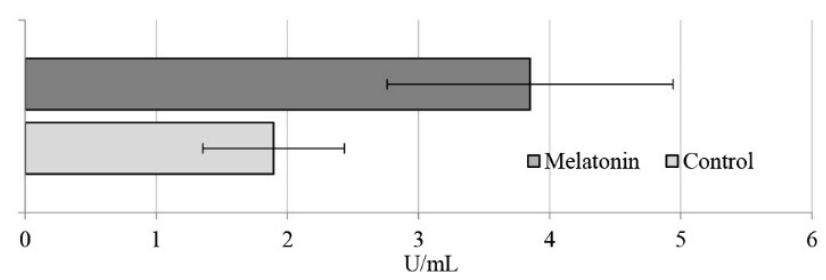

Fig. 2. Catalase activity (mean \pm SE). 
Table 1. Mean body weight (BW) of chickens of different age.

\begin{tabular}{ccc}
\hline Age of chicken (days) & BW (g) & $\begin{array}{c}\text { Control group } \\
\text { Mean } \pm \text { SE }\end{array}$ \\
\hline 1 & Mean \pm SE & $41.33^{\mathrm{a}} \pm 0.23$ \\
7 & $40.93^{\mathrm{a}} \pm 0.27$ & $140.70^{\mathrm{b}} \pm 1.26$ \\
14 & $150.36^{\mathrm{a}} \pm 1.30$ & $336.75^{\mathrm{b}} \pm 4.15$ \\
21 & $359.24^{\mathrm{a}} \pm 4.48$ & $649.68^{\mathrm{b}} \pm 11.13$ \\
28 & $727.98^{\mathrm{a}} \pm 11.09$ & $1032.32^{\mathrm{b}} \pm 18.37$ \\
35 & $1128.68^{\mathrm{a}} \pm 17.44$ & $1537.92^{\mathrm{b}} \pm 26.25$ \\
42 & $1671.09^{\mathrm{a}} \pm 24.81$ & $2114.05^{\mathrm{b}} \pm 31.21$ \\
\hline
\end{tabular}

$\mathrm{a}, \mathrm{b}$ - Values within a row with different superscripts differ significantly at $\mathrm{P}<0.01$.

SE - Standard Error.

Table 2. Mean values of daily weight gain (WG), feed intake (FI), and feed conversion ratio (FCR) by weeks.

\begin{tabular}{ccccccc}
\hline \multirow{2}{*}{ Weeks } & \multicolumn{2}{c}{ WG (g) } & \multicolumn{2}{c}{ FI (g/day) } & \multicolumn{2}{c}{ FCR (kg/kg) } \\
& Melatonin & Control & Melatonin & Control & Melatonin & Control \\
& Mean \pm SE & Mean \pm SE & Mean \pm SE & Mean \pm SE & Mean \pm SE & Mean \pm SE \\
\hline 1 & $15.64^{\mathrm{a}} \pm 0.15$ & $14.49^{\mathrm{b}} \pm 0.15$ & $24.07 \pm 0.64$ & $22.65 \pm 0.45$ & $1.53 \pm 0.05$ & $1.56 \pm 0.02$ \\
2 & $29.84^{\mathrm{a}} \pm 0.48$ & $27.72^{\mathrm{b}} \pm 0.42$ & $47.61 \pm 0.71$ & $45.47 \pm 0.77$ & $1.60 \pm 0.04$ & $1.64 \pm 0.04$ \\
3 & $52.98^{\mathrm{a}} \pm 0.97$ & $45.20^{\mathrm{b}} \pm 1.01$ & $88.39 \pm 0.70$ & $80.72 \pm 1.94$ & $1.68 \pm 0.03$ & $1.81 \pm 0.05$ \\
4 & $57.24^{\mathrm{a}} \pm 0.97$ & $54.66^{\mathrm{b}} \pm 1.07$ & $108.46 \pm 2.25$ & $106.80 \pm 2.24$ & $1.90 \pm 0.02$ & $1.95 \pm 0.01$ \\
5 & $77.49^{\mathrm{a}} \pm 1.25$ & $72.23^{\mathrm{b}} \pm 1.33$ & $150.5 \pm 5.71$ & $147.16 \pm 3.27$ & $1.94 \pm 0.01$ & $2.04 \pm 0.04$ \\
6 & $86.80^{\mathrm{a}} \pm 1.01$ & $82.30^{\mathrm{b}} \pm 1.00$ & $181.47 \pm 2.57$ & $168.74 \pm 5.74$ & $2.10 \pm 0.08$ & $2.06 \pm 0.03$ \\
\hline
\end{tabular}

$\mathrm{a}, \mathrm{b}$ - Values within a row with different superscripts differ significantly at $\mathrm{P}<0.01$.

$\mathrm{SE}$ - Standard Error.

\section{Discussion and Conclusion}

Melatonin is a hormone of primary importance for the health and welfare of animals in all stages of life (2). Exposure to light is equally significant for young chicken organism's normal development and functioning as having a certain level of melatonin in the blood. According to welfare standards (27), broilers should not be exposed to light for a certain period during the day to ensure a diurnal melatonin cycle. In this experiment, after the broilers' prolonged exposure to the constant lighting, 14 days instead of the usual 7 (7), the adverse effects have not been recorded. Generally, the addition of melatonin has had a positive effect on blood parameters and production parameters. The absence of statistically significant differences in all blood parameters is probably a consequence of the small number of samples in this study.

The blood profile of poultry differs depending on age and many other factors $(34,35)$. Thus, the mean values of $\mathrm{RBC}$ (and other hematological parameters) in both groups can be considered as usual for young Ross hybrid chickens per Rusov (28) but are not consistent with data from other authors $(4,34,35)$. Melatonin protects erythrocytes and the heme group from damage caused by oxidative stress and consequently from the shortening of life expectancy $(20,37)$, which might be the reason for slightly higher values of these parameters in the $\mathrm{M}$ group. An increase in the number of erythrocytes of the same volume (MCV) increases the hematocrit values. Higher hemoglobin values are associated with higher $\mathrm{MCH}$ and $\mathrm{MCHC}$ values, as seen from the calculation formulas.

A higher number of white blood cells in the $\mathrm{M}$ group may be related to the immunostimulatory effect of melatonin as in the experiment by Brennan et al. (12). Melatonin stimulates lymphocyte, monocyte, and eosinophil production $(15,16,41)$. In an experiment on quails (22), similar results to ours have obtained: the addition of melatonin led to an increase in total leukocyte count (WBC), an increase in lymphocyte, and a decrease in heterophile percentages, and a decrease in heterophile/lymphocyte ratio; the shortening of the photoperiod had the same effect (which affected the physiological increase of melatonin in the organism). The ratio between heterophiles and lymphocytes $(\mathrm{H} / \mathrm{L}$ ratio) indicates a stress response in poultry. In response to 
stressors, the number of lymphocytes decreases, and the number of heterophiles increases $(21,30)$. Continuous lighting is stressful to broilers, but melatonin administration ameliorates the adverse effects of photostressful conditions in birds (19). A higher $\mathrm{H} / \mathrm{L}$ value in the $\mathrm{C}$ group indicates a more pronounced stress response, so the values obtained in the $\mathrm{M}$ group show that birds who received melatonin tolerated the ambient conditions and the applied lighting regime better, compared to the chickens from the control group.

The fast growth rate in broilers is associated with rapid cell proliferation. Consequently, the higher level of reactive oxygen species (ROS) increasingly leads to oxidative stress, disturbing many metabolic and immunological pathways (23). One of the main antioxidative enzymes that are stimulated by melatonin under basal conditions is catalase (CAT). Melatonin supplement to the diet has had a stimulatory effect on CAT activity in group $\mathrm{M}$, similar to that described by Reiter et al. (26).

The addition of melatonin to the diet of broiler chickens reared under 24L: 0D regime during the first 14 days of life showed a more pronounced positive effect on body weight and daily gain of broilers $(\mathrm{P}<0.01)$, which is consistent with the results of Akbarian et al. (3). Melatonin stimulates the synthesis of growth hormone (GH) in the pituitary gland and its secretion into the bloodstream by acting on the hypothalamus and thus has a positive effect on broiler growth performance (14) and energy metabolism (38). Considering the GH level in broiler plasma is the highest in the early phase of age (29) that probably manifested in our results. Decreased broiler activity also affects the gain of body weight (5), and it occurred from the third week of the experiment with a shortening of the photoperiod.

The positive effect of melatonin supplementation in the first two weeks on chicken growth continued throughout the end of the fattening period. Regarding feed consumption and conversion, there was no significant effect of melatonin supplementation. Still, it is evident that daily feed intake was higher, and the FCR was lower in the M group compared to the control group in all weeks of the experiment. FCR values are consistent with relevant data from other research (3). The treatment in group M led to more efficient fattening as compared to the control, which is confirmed by a significant difference in EPEF values $(\mathrm{P}<0.05)$.

Defining the optimal light and nutritional management is still a challenge in the poultry industry, where achieving high production goals is expected, along with preserving animal health and welfare. One way is the oral administration of melatonin and its precursor tryptophan, which has been recommended by many authors to alleviate the effects of stressors to which birds are exposed in conditions of intensive production $(1,3,14$, 23). Our results confirmed that melatonin feed supplementation to broilers enhanced their growth and productivity. Furthermore, melatonin administration alleviated the detrimental effects of continuous lighting on broilers. The presented results indicate a direct benefit of stress relief and a value of the organism's antioxidant system promotion, which was manifested by improved production performances and fattening efficiency in broilers.

\section{Financial Support}

This research was funded by the Ministry of Education, Science and Technological Development, Republic of Serbia, contracts No 451-03-68/2020$14 / 200116$ and 451-03-68/2020-14/200022.

\section{Ethical Statement}

The trial was performed at the Institute for Animal Husbandry, Belgrade, Serbia, at the Experimental Broiler Farm. The experiment and experimental procedures were evaluated by the Ethics Committee of the Institute, and approved by the Veterinary Directorate in MAFW of the Republic of Serbia (Approval No: 323-07-00069/201705).

\section{Conflict of Interest}

The authors declare that there is no conflict of interest.

\section{References}

1. Abbas A, Gehad A, Hendricks G, et al (2007): The effect of lighting program and melatonin on the alleviation of the negative impact of heat stress on the immune response in broiler chickens. Int J Poult Sci, 6, 651-660.

2. Ahmed HH, Essawy GS, Salem HA, et al (2011): Effect of Melatonin on Some Hematological Parameters and Immune Status of Broiler Chicks. J Agric Sci, 3, 243-254.

3. Akbarian A, Kazerani HR, Mohri M, et al (2014): Exogenous melatonin improves growth performance, intestinal microbiota and morphology in temporarily feed restricted broilers. Livest Sci, 167, 400-407.

4. Amao SR, Oyewumi SO (2017): Influence of Age and Strain on Haematological and Blood Biochemical Indices in Broiler Chickens Reared in Derived Savanna Environment of Nigeria. Am J Life Sci, 5, 34-38.

5. Apeldoorn EJ, Schrama JW, Mashaly MM, et al (1999): Effect of Melatonin and Lighting Schedule on Energy Metabolism in Broiler Chickens. Poult Sci, 78, 223-229.

6. Arowolo M, He H, He S, et al (2019): The implication of lighting programmes in intensive broiler production system. Worlds Poult Sci J, 75, 17-28.

7. Aviagen (2014): ROSS 308 Broiler Management Handbook. Available at Ross-308-Broiler-PO-2014-EN.pdf (winmixsoft.com) (Accessed 15 September 2020).

8. Aviagen (2014): Ross 308 Broiler Nutrition Specifications. Available at http://en.aviagen.com/assets/Tech_Center 
/Ross_Broiler/Ross308BroilerNutritionSpecs2014-EN.pdf. (Accessed 15 September 2020).

9. Berger J (2004): Regulation of circadian rhythms. J Appl Biomedicine, 2, 131-140.

10. Beutler E (1984): Red cell metabolism, In: Beutler, E. (Ed.), A Manual of Biochemical Methods. $3^{\text {rd }}$ ed. Grune and Stratton, New York.

11. Božić T, Gvozdić D (1995): Pathological physiology of domestic animals (selected chapters and practicum). The University of Belgrade, Veterinary Faculty, Belgrade.

12. Brennan CP, Hendricks GL III, El-Sheikh TM, et al (2002): Melatonin and the Enhancement of Immune Responses in Immature Male Chickens. Poult Sci, 81, 371-375.

13. Bubenik GA (2002): Gastrointestinal melatonin: Localization, Function, and Clinical Relevance. Dig Dis Sci, 42, 2336-2348.

14. Çalışlar S, Yeter B, Şahin A (2018): Importance of Melatonin on Poultry. KSÜ Tar Doğa Derg, 21, 987-997.

15. Calvo JR, Gonzalez-Yanes C, Maldonado MD (2013): The role of melatonin in the cells of the innate immunity: a review. J Pineal Res, 55, 103-120.

16. Carrillo-Vico A, Lardone PJ, Álvarez-Sánchez $N$, et al (2013): Melatonin: Buffering the Immune System. Int J Mol Sci, 14, 8638-8683.

17. Cassone VM, Paulose JK, Whitfield-Rucker MG, et al (2009): Time's arrow flies like a bird: two paradoxes for avian circadian biology. Gen Comp Endocrinol, 163, 109-116.

18. Csernus V, Mess B (2003): Biorhythms and pineal gland. Neuro Endocrinol Lett, 24, 404-411.

19. Egbuniwe C, Ayo J (2016): Physiological roles of avian eyes in light perception and their response to photoperiodicity. Worlds Poult Sci J, 72, 605-614.

20. Farag H, Ali Hassan R, Al Lehyani SH (2020): Protective effect of melatonin on hemoglobin damage induced by gamma irradiation. JETIR, 7, 320-325. Available at: http://www.jetir.org/papers/JETIR1912042.pdf (Accessed 13 September 2020).

21. Gross WB, Siegel HS (1983): Evaluation of the heterophil/lymphocyte ratio as a measure of stress in chickens. Avian Dis, 27, 972-979.

22. Moore CB, Siopes TD (2000): Effects of light conditions and melatonin supplementation on the cellular and humoral immune responses in Japanese quail Coturnix coturnix japonica. Gen Comp Endocrinol, 119, 95-104.

23. Mund MD, Riaz M, Mirza MA, et al (2019): Effect of dietary tryptophan supplementation on growth performance, immune response and anti-oxidant status of broiler chickens from 7 to 21 days. Vet Med Sci, 6, 48-53.

24. Olanrewaju H, Thaxton J, Dozier W, et al (2006): $A$ review of lighting programs for broiler production. Int $\mathrm{J}$ Poul Sci, 5, 301-308.

25. Pattison M (2008): Poultry Diseases. Elsevier Health Sciences, Amsterdam.

26. Reiter R, Tan D, Galano A (2014): Melatonin: Exceeding expectations. Physiol, 29, 325-333.
27. RSPCA (2017): RSPCA welfare standards for meat chickens. Available at: https://science.rspca.org.uk/ sciencegroup/farmanimals/standards/chickens (Accessed 12 June 2020).

28. Rusov Č (2002): Hematology of birds. Scientific Veterinary Institute of Serbia (NIVS). Belgrade.

29. Scanes C, Lauterio T (1984): Growth hormone: Its physiology and control. J Exp Zool, 232, 443-452.

30. Singh R., Cook N., Cheng K. M., et al (2009): Invasive and noninvasive measurement of stress in laying hens kept in conventional cages and in floor pens. Poult Sci, 88, $1346-1351$.

31. Sinkalu V (2012): Effect of melatonin on physiological responses of broiler chickens to continuous lighting, heat and road transportation stress during the hot-dry season. Doctoral Dissertation. Department of Physiology, Faculty of Veterinary medicine, Ahmadu Bello University, Zaria, Nigeria.

32. Sun YY, Li YL, Li DL, et al (2017): Responses of broilers to the near-continuous lighting, constant 16-h lighting, and constant 16-h lighting with a 2-h night interruption. Livest Sci, 206, 135-140.

33. Škrbić Z, Pavlovski Z, Lukić M, et al (2013): The role of light in broiler production. 222-231. In: Proceedings $10^{\text {th }}$ International Symposium "Modern Trends in Livestock Production", Belgrade.

34. Talebi A, Asri-Rezaei S, Rozeh-Chai R, et al (2005): Comparative Studies on Haematological Values of Broiler Strains (Ross, Cobb, Arbor-acres and Arian). Int J Poult Sci, 4, 573-579.

35. Tehrani A, Javanbakht J, Askari S, et al (2012): Haematological Studies on Broiler Chickens Fed with Different Levels of Artemia Urmiana. J Biotechnol Biomater, 2, 138.

36. Weiss DJ, Wardrop JK (2011): Schalm's Veterinary Hematology. Sixth Edition. Wiley-Blackwell. Washington.

37. Zavodnik IB, Domanski AV, Lapshina EA, et al (2006): Melatonin directly scavenges free radicals generated in red blood cells and a cell-free system: Chemiluminescence measurements and theoretical calculations. Life Sci, 79, 391-400.

38. Zeman M, Buyse J, Lamošova D, et al (1999): Role of melatonin in the control of growth and growth hormone secretion in poultry. Appl Anim Behav Sci, 17, 199-207.

39. Zeman M, Herichova I (2011): Circadian melatonin production develops faster in birds than in mammals. Gen Comp Endocrinol, 172, 23-30.

40. Zhao D, Yu Y, Shen Y, et al (2019): Melatonin synthesis and function: Evolutionary history in animals and plants. Front Endocrinol, 10, 249.

41. Zheng L, Ma Y, Gu L, et al (2013): Growth performance, antioxidant status, and nonspecific immunity in broilers under different lighting regimes. J Appl Poult Res, 22, 798807. 